\title{
Correction to: RiseTx: testing the feasibility of a web application for reducing sedentary behavior among prostate cancer survivors receiving androgen deprivation therapy
}

\author{
Linda Trinh ${ }^{1 *}$, Kelly P. Arbour-Nicitopoulos ${ }^{1}$, Catherine M. Sabiston ${ }^{1}$, Scott R. Berry², Andrew Loblaw²,
} Shabbir M. H. Alibhai ${ }^{3}$, Jennifer M. Jones ${ }^{4}$ and Guy E. Faulkner ${ }^{5}$

Correction to: Journal of Behavioral Nutrition and Physical Activity (2018) 15:49

https://doi.org/10.1186/s12966-018-0686-0

Following publication of the original article [1], the author has requested us to make a correction in the Results section of the Abstract and in the Discussion sections as explained below:

1. In the results section of the abstract, it should read 'Overall adherence was $72 \%$ for total number of logins (i.e., $>3$ visits each week)' instead of 'Overall adherence was $64 \%$ for total number of logins (i.e., $>3$ visits each week)'.

2. In the discussion section of the abstract, it should read 'Our study had an overall adherence rate of $72 \%$ that while higher than previous studies, still represents difficulties with engagement' instead of 'Our study had an overall adherence rate of $64 \%$ that while higher than previous studies, still represents difficulties with engagement.'

\footnotetext{
Author details

${ }^{1}$ Faculty of Kinesiology and Physical Education, University of Toronto, Toronto, ON, Canada. ${ }^{2}$ Sunnybrook Odette Cancer Centre, Toronto, ON, Canada. ${ }^{3}$ Department of Medicine, University Health Network \& University of Toronto, Toronto, ON, Canada. ${ }^{4}$ Cancer Survivorship Program, Princess Margaret Cancer Centre, Toronto, ON, Canada. ${ }^{5}$ School of Kinesiology, University of British Columbia, Vancouver, BC, Canada.
}

Published online: 04 December 2018

\section{Reference}

1. Trinh $L$, et al. RiseTx: testing the feasibility of a web application for reducing sedentary behavior among prostate cancer survivors receiving androgen deprivation therapy. Int J Behav Nutr Phys Act. 2018;15:49. https://doi.org/ $10.1186 /$ s12966-018-0686-0.

\footnotetext{
* Correspondence: linda.trinh@utoronto.ca

${ }^{1}$ Faculty of Kinesiology and Physical Education, University of Toronto,

Toronto, ON, Canada

Full list of author information is available at the end of the article
}

(c) The Author(s). 2018 Open Access This article is distributed under the terms of the Creative Commons Attribution 4.0 International License (http://creativecommons.org/licenses/by/4.0/), which permits unrestricted use, distribution, and reproduction in any medium, provided you give appropriate credit to the original author(s) and the source, provide a link to the Creative Commons license, and indicate if changes were made. The Creative Commons Public Domain Dedication waiver (http://creativecommons.org/publicdomain/zero/1.0/) applies to the data made available in this article, unless otherwise stated. 